Proceedings of the Creative Construction Conference (2018)

Edited by: Miroslaw J. Skibniewski \& Miklos Hajdu

DOI 10.3311/CCC2018-096

Creative Construction Conference 2018, CCC 2018, 30 June - 3 July 2018, Ljubljana, Slovenia

\title{
A Framework for Modelling Masonry Construction Using Hybrid Simulation Approaches
}

\author{
Orsolya Bokor, Laura Florez, Allan Osborne, Barry J. Gledson \\ Northumbria University, Newcastle, United Kingdom
}

\begin{abstract}
Labour is a crucial resource for construction projects. More risks are associated with this than with other resources, such as materials and equipment. Contractors need tools to make more precise estimations concerning labour productivity that will allow them to minimise these risks and manage labour resources in the most efficient way possible. To achieve this, use can be made of construction simulation techniques, however, depending on the complexity of the problem, applying a single simulation approach might not be enough to appropriately model construction. Hybrid simulation approaches seem to be suitable because they combine the advantages of their components to reflect the dynamic nature of construction processes better and consider the number of uncertainties. Hybrid approaches can combine traditional discrete-event simulation (DES), agent-based modelling (ABM) or system dynamics (SD) with each other or with, for example, fuzzy logic (FL) to better capture the factors influencing productivity. To address these issues, a framework for modelling a masonry construction process that uses hybrid simulation is presented. Because masonry works are one of the most labour-intensive construction processes, and skilled labour resources are scarce, the use of such a framework would help contractors to make more realistic schedules based on accurate labour productivity estimation; thus, enabling them to utilise their resources more efficiently.
\end{abstract}

(C) 2018 The Authors. Published by Diamond Congress Ltd., Budapest University of Technology and Economics Peer-review under responsibility of the scientific committee of the Creative Construction Conference 2018.

Keywords: agent-based modelling, discrete-event simulation, fuzzy logic, hybrid simulation, masonry, productivity, scheduling, system dynamics.

\section{Introduction}

Construction project success is usually measured by the triumvirate constructs of cost, time and quality, which directly affect labour productivity. Even though there have been efforts to use prefabricated elements, construction projects can still be considered labour-intensive works. As a result, forming active crews is critical to successful projects. Before construction, to make cost calculations and schedules reflect reality, reasonable estimates of labour productivity are essential.

Construction simulation, which has evolved since the development of computers, is a useful method for modelling 'workflow' that provides professionals with productivity data. Gordon [1] suggested a general-purpose simulation program to solve problems arising from telecommunications to manufacturing. Teicholz's [2] link-node model that was developed in 1963 could be considered the forerunner of construction simulation. Since then several different approaches have been proposed.

Most of the existing literature on construction simulation introduces earthworks (see, for example, AbouRizk and Halpin [3], Alzraiee, Zayed and Moselhi [4], Lorterapong and Moselhi [5]), reinforced concrete works (see, for example, Khanzadi et al. [6], Moradi, Nasirzadeh and Golkhoo [7], Nojedehi and Nasirzadeh [8]) or civil engineering works (see, for example, AbouRizk and Sawhney [9], AbouRizk [10], Robinson Fayek and Oduba [11]) as case studies, which are mostly machine-driven works. However, it is arguably more important to simulate labour-driven works as labour resources tend to be scarcer (especially skilled) and more risks are involved with them than with equipment or

Corresponding author: Orsolya Bokor, email: orsolya.bokor@ northumbria.ac.uk 
materials. The focus of the paper will be concentrated on masonry construction, which is a labour-intensive work, and a traditional element of a construction project. Accepting that some materials have changed over the centuries, masonry remains a vital part of many projects, such as housing. Furthermore, the possible application of a developed framework for other labour-driven works needs to be considered in the future.

The remainder of this paper firstly introduces the basic simulation approaches, then overviews hybrid simulation approaches. Next, a framework is presented for the utilisation of simulation in case of masonry construction projects. Finally, the conclusions are drawn, and the direction of future research in the topic is set.

\section{Basic simulation approaches}

One of the essential simulation approaches is a discrete-event simulation (DES), which focuses on, and models the process itself. The first notable construction simulation tool using DES was Halpin's CYCLONE (CYCLic Operations Network) in 1973, which was intended to be a general-purpose simulation system [2]. Martinez [12] has described a methodology for conducting DES that draws attention to the possible problems, which could put the model's validity in jeopardy [12]. Activity durations in DES models can be described by probability distribution functions like the ones used in Program Evaluation and Review Technique (PERT). Law [13] attempted to collect all the available functions (ranging from uniform to Weibull, including the Johnson and Pearson systems) with their properties and explained their usage in case of simulations. AbouRizk and Halpin [3] suggested that flexible functions are needed due to the 'diversified nature of construction duration data' [3, p. 537], and advised the use of the beta function because of its familiarity in the construction field. Hajdu and Bokor [14] argued that a careful three-point estimation is more important than the type of distribution function selected. Monte Carlo simulations performed on hypothetical and reallife projects showed that a $10 \%$ difference in the three-point estimation causes greater deviations than the chosen distributions [14].

Another simulation approach is system dynamics (SD), which was developed by Forrester [15] at the beginning of the 1960s. SD is a top-down method concentrating on the various influencing factors and the relationships among them showing the entire system's workings with feedback loops [15]. SD can be used for both qualitative and quantitative modelling: the former focuses on creating a causal loop diagram, while the latter determines stocks and flows and expresses the links with equations [16]. Mawdesley and Al-Jibouri [17] used SD to determine which areas should be improved by the management to increase productivity. The model contained planning, control, motivation, safety and disruptions as the most significant factors. Several strategies were tested, and it was found that the first two need the management's particular attention [17].

In contrast to SD, agent-based modelling (ABM) has a bottom-up approach: the system's behaviour emerges from how heterogenous agents interact with each other and their environment based on the defined rules. Siebers et al. [18] argued that ABM had an advantage over DES, in cases where the focus is not on the process but on how the individual agents, who can learn and adapt, can affect the system. Son, Rojas and Shin [19] emphasised similar positive properties through examples of project teams in large-scale construction projects. They recommended ABM for modelling, for instance, the international construction market with countries and firms as agents [19]. Sawhney et al. [20] advised the usage of ABM to increase construction safety on site by modelling the construction environment, workers with various tolerance towards risk (agents) and safety management practices. Watkins et al. [21] used ABM to determine how site congestion affects productivity; two agent types were defined: workers (with variables such as skill level) and activities [21]. Dabirian, Khanzadi and Moussazadeh [22] applied the same two agents in order to estimate labour costs better. Hsu et al. [23] applied ABM to assess team member selection models. In their research, the agents were the workers with attributes such as experience and skills. It was concluded that interdependence-based selection is preferable to skill-based assignment [23].

\section{Hybrid simulation approaches}

The approaches described above are often used individually but can also be applied in combination. A benefit of the combined approach is to use the various advantages of each method and to balance its shortcomings. The most suitable approach should be selected for each component of the model and, depending on the question that needs to be answered, the combination will provide a replica of reality [24] and [25].

Different names exist for these combined approaches, including: 'hybrid', 'multi-method', and 'multi-paradigm' [26]. Mosterman [27] defined the composite of discrete and continuous simulation as 'hybrid simulation'. Balaban, Hester and Diallo [28] argued that ABM might not be considered a paradigm; hence, those approaches where ABM is 
paired with another method may not be called multi-paradigm. According to them [28], there is also a distinction between mixed/hybrid and multi-methods. Both Mustafee et al. [26] and Balaban, Hester and Diallo [28] agree that proper definitions are needed.

Furthermore, the three basic simulation approaches can be mixed with methods, such as neural networks (NN) or fuzzy logic (FL) [28]. These could also be considered hybrid approaches [8] and [10].

However, in this paper, the term 'hybrid simulation' refers to any method where a basic simulation approach is combined with either another basic simulation approach or fuzzy logic.

\subsection{The possible combinations of the basic simulation approaches}

Fahrland [29] suggested the combination of DES and SD to create improved, more realistic, more efficient models. According to him [29], there are many possible applications for these hybrids from aerospace missions to nuclear power plant start-ups. While DES concentrates on the process, dealing with issues on the operational level, SD is suitable for modelling on the strategic level; thus, complementing each other [30]. With the help of combined DESSD systems, it is possible to coordinate managerial and operational decisions to increase productivity [30] and [31]. In the interest of obtaining more realistic project duration data, Alzraiee, Zayed and Moselhi [32] complemented DES with SD as well. The latter was used to take the affecting factors (for instance, weather and overtime) into consideration.

DES can also be combined with ABM. In operational research, instead of pure ABM, mostly a hybrid model is used where the entities of the DES are active, ABM agents [18]. The same is true in healthcare, where simple DES models are rare, and instead, ABM is used within DES [26] (see, for example, Borshchev [24]).

Lättilä, Hilletofth and Lin [33] urged that researchers should combine SD with ABM to combine the positive features of both approaches. They also mentioned that both systems could be used to model the same problem and then the results could be compared [33]. Nasirzadeh, Khanzadi and Mir [34] proposed an integrated SD-ABM simulation approach to model construction workers' safety behaviour and its effect on the project duration. In the ABM model, contractors were chosen as agents, and each of them had their SD models showing the influencing factors. There was constant information flow between the models [34]. Khanzadi et al. [6] also used an integrated SD-ABM simulation approach to see how site congestion affects productivity.

Borshchev [24] provided an example for combining all three basic approaches where DES is used to model the supply chain process, SD describes the market, and the participants are represented by agents.

\subsection{Using fuzzy logic}

Mixing the basic approaches with each other is not the only option to improve the models. Another possibility is to use, for example, fuzzy logic (FL). Zadeh [35] stated that the nature of the problem determines whether probability theory, fuzzy logic (FL) or a combination of these is required for the solution. FL is preferred in cases of uncertainty and imprecise data, which is 'nonstatistical in nature' [35, p. 421]. Ayyub and Haldar [36] proposed the use of FL for including uncertainties given in linguistic terms in project schedules. Weather conditions and the experience of the workers were arbitrarily selected as factors in their example. The modified activity durations were calculated based on the frequency of occurrence of the factors, their negative effects on the duration and the membership functions [36]. Robinson Fayek and Oduba [11] analysed two activities from a real-life industrial construction project with the help of FL, collected the factors affecting productivity (in two sub-models to decrease the size of the model) and the related 'if-then' rules. Triangular and trapezoidal membership functions were used, complete with experts' estimates for the endpoints. Then, these results were compared to actual project data [11]. With the number of factors increasing, the amount of rules grows exponentially; therefore, Shaheen, Robinson Fayek and Abourizk [37] proposed to gather the related factors under blocks. Lorterapong and Moselhi [5] introduced FNET (fuzzy network scheduling), in case there is no available historical data or fair expert estimate. The proposed method produces more realistic results in the backward pass, affecting criticality [5].

Raoufi, Seresht and Robinson Fayek [38] provided an extensive overview of the combinations of FL with DES, SD and $\mathrm{ABM}$ in construction, showing the advantages of integrating FL into the basic approaches and giving advice on the appropriate choice of a hybrid technique.

AbouRizk and Sawhney [9] developed SIDES (subjective and interactive duration estimation system) with the aim of determining more realistic beta distribution functions for activity durations in DES with the help of FL. The users of the application had to define the two endpoints of the function; however, fitting was based on the selected influencing 
factors expressed in linguistic terms [9]. Zhang, Tam and Li [39] also suggest the application of FL in DES in cases when there is no field data to use. Even when there is, FL could be used to incorporate 'vagueness, imprecision and subjectivity' [39, p. 727].

Khanzadi, Nasirzadeh and Alipour [40] integrated FL into SD to determine the ideal concession period in case of build-operate-transfer projects. The influencing factors with their causal loops made up the SD module, while the magnitude of the factors was calculated by FL [40]. De Salles, Gonçalves Neto and Marujo [41] applied the same combination to evaluate business decision policies. The critical factors influencing the system were modelled in SD, while FL translated the policies given in linguistic terms into the SD model [41]. Nojedehi and Nasirzadeh [8] also combined SD with FL, while the former part of the model contained the most important factors influencing labour productivity; the latter component was used to express the effect of those factors that could not have been done with crisp values. With the help of the model, possible solutions for improving productivity were tested to contribute to better managerial decisions [8].

Raoufi and Robinson Fayek [42] combined FL with ABM to investigate how crew performance is affected by the workers' personality, their interactions with each other and their environment. Two layers of agents were defined: workers and crews. The 'what-if' rules of agent behaviour were expressed in linguistic terms, which were translated using FL [42].

\subsection{The structure of hybrid simulation models}

Selecting which approaches will make up the hybrid to solve a given problem is only the first step. Next, the structure must be determined. There are numerous options that explain how the methods could be combined. Borshchev [24] described the six most frequently used variations and provided examples for all of them. These are [24]:

- agents in an SD environment

- agents interacting with a DES model

- DES model linked to an SD model

- SD inside agents

- DES inside agents

- agents as entities in a DES model

Moradi, Nasirzadeh and Golkhoo [7] defined three possible ways the DES and SD models could be linked. First is the hierarchical format, which could either be SD- or DES-dominant. In this case, there is a vertical interaction between the strategic (SD) and operational (DES) models. The second one is the phase-to-phase format, where the two models run in separate phases. The third type is the integrated format, which allows constant bidirectional interactions [7]. Alvanchi, Lee and AbouRizk [31] also identified three structures of DES-SD hybrid models similar to the ones mentioned above [7]. These are the DES-dominant, SD-dominant and parallel modelling. In the case of the first two, the direction of the interaction is towards the dominant part, while in parallel models, the interaction is bidirectional.

Swinerd and McNaught [43] defined three classes for SD-ABM hybrid simulation. In the case of the integrated simulation, there is continuous feedback both ways between the two modules. Sequential simulation means that first, the SD module runs, and its output becomes the input for the ABM module or vice versa. The third class is interfaced hybrid design, where the modules run parallel and their outputs are combined [43].

\subsection{Interface variables in the hybrid simulation}

After the most suitable structure is selected, the interaction points between the components need to be defined. These interface variables are the ones that may affect the variables in the other component. According to Alvanchi, Lee and AbouRizk [31], there are five types of interactions:

- in case of one discrete and one continuous variable

$O$ a discrete change in the discrete variable causes a discrete change in the continuous one

$O$ a discrete change in the discrete variable causes a change in the functional description of the continuous one

$O$ a continuous change in the continuous variable causes a discrete change in the discrete one

- in case of two continuous variables

$O$ a continuous change in one continuous variable causes a continuous change in the other

- in case of two discrete variables

$O$ a discrete change in one discrete variable causes a discrete change in the other 


\section{Simulation framework}

The framework for construction simulation can be seen in Figure 1. The first step in the process is to analyse the problem at hand. Based on whether a simple or a complicated question needs to be answered, or whether the part of reality to be modelled is simple or complex, the left or the right path should be chosen respectively. The next step is to select the most appropriate simulation approach. The choice could be made based on the purpose of the investigation and the required level of abstraction. The basic approaches provide different levels of abstraction. If the focus is on the process itself, DES might be the most suitable approach, as it could be used on the operational level. It provides information on activity and project durations and resources. In DES, the workflow of the masonry process needs to be modelled. For the construction masonry unit, the description of the workflow could be found in Florez and CastroLacouture's work [44], whereas Dawood, Hobbs and Fanning [45] provide the same for brickwork. SD concentrates on causal relationships on a macro level and tracks the changes of the continuous variables. In the case of masonry, it could be used, for example, to include the factors influencing labour productivity. ABM may be applied at all levels of abstraction. By defining the agents with their attributes and rules of behaviour, the workings of the global system are revealed. The agents, for instance, could be masons and labourers working on a project. The most critical variables concerning the workers are described in Florez's work [46]. The different wall sections could also be agents. Florez [46] and Thomas and Završki [47] provide possible classifications for walls in masonry construction. FL is useful in case the variables are subjective and could not be easily expressed with crisp values.

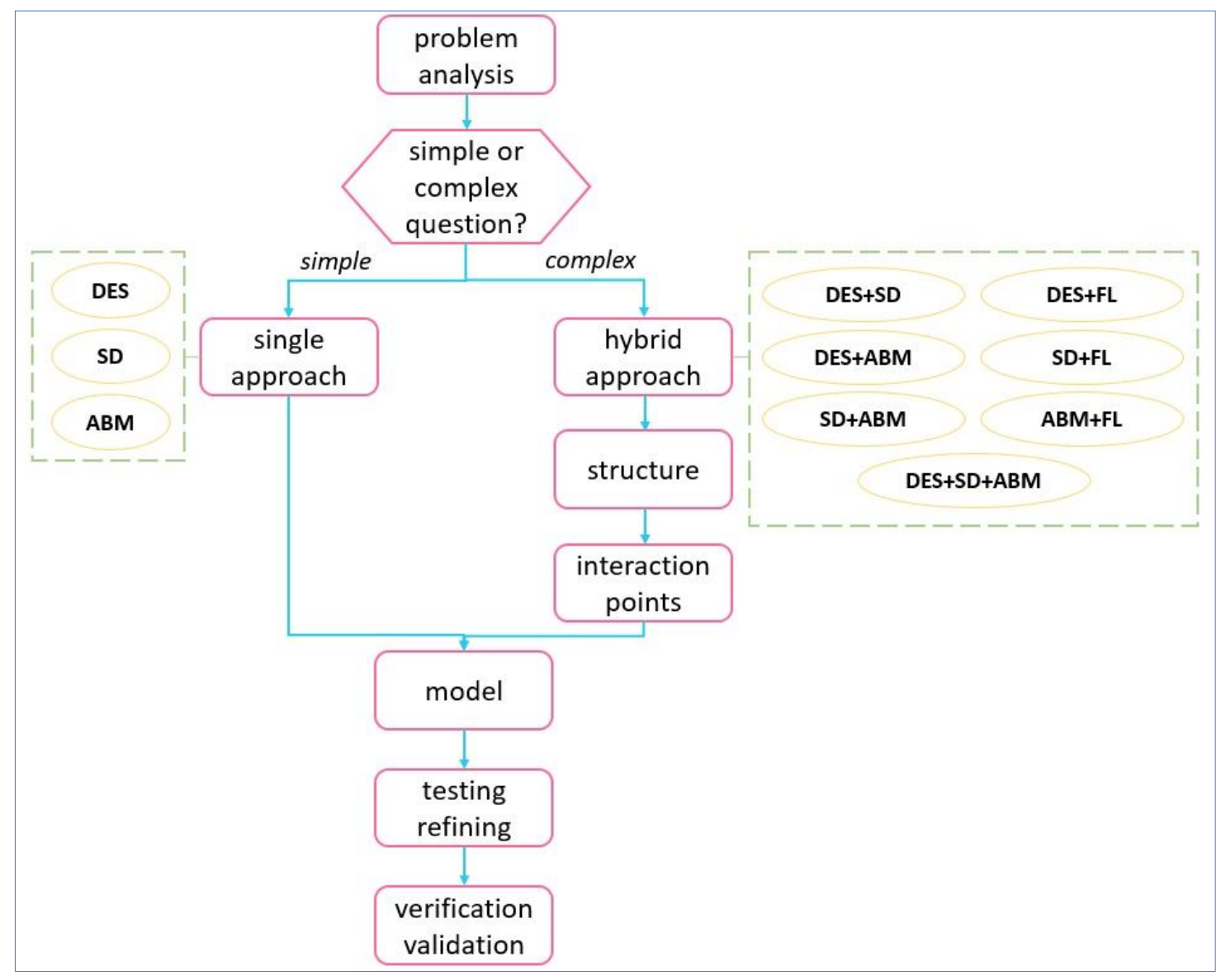

Figure 1. Construction simulation framework 
If a hybrid solution seems appropriate, after choosing the most suitable approach, the structure must be determined. It could be one of the following:

- integrated: the interaction between the components is bidirectional and continuous

- dominant: one approach is more dominant than the other, and this determines the direction of the interaction, which will be towards the more dominant component

- parallel: the components are running simultaneously, and their outputs are combined

The next step in this branch is to define the interface variables described in section 3.4.

Based on the selected simulation approach, its structure and interaction points, if applicable, and the required input data, the simulation model could be produced. Afterwards, this needs to be tested and refined.

The ready model must be checked as well. Verification confirms that the model is a correct reflection of reality, whereas validation is performed to show that the model's accuracy is adequate for the simulation problem. Verification and validation, in fact, do not only happen at the end, but they are performed after every step in the model development process [48].

\section{Conclusion}

Construction simulation is a useful tool, which replicates reality; thus, providing valuable information on construction works. It could be applied to gain better productivity estimates to make more realistic schedules and cost calculations.

This paper explained a framework for construction simulation. Since construction projects are complex, and many uncertainties are involved, probably the most suitable simulation approaches could be found among hybrid simulation solutions. These combine the advantages of the selected techniques in order to better model reality.

Empirical research is needed to test the framework by using real-life case studies of masonry projects. It also must be checked whether specific approaches and structures are better suited for modelling masonry works than others. Furthermore, it must be investigated whether the system could be used in case of other labour-intensive works.

\section{References}

[1] G. Gordon, "A general purpose systems simulation program," in Proceedings of the December 12-14, 1961, Eastern Joint Computer Conference: Computers - Key to Total Systems Control - AFIPS '61 (Eastern), 1961, pp. 87-104.

[2] S. AbouRizk, D. Halpin, Y. Mohamed, and U. Hermann, "Research in Modeling and Simulation for Improving Construction Engineering Operations," J. Constr. Eng. Manag., vol. 137, no. 10, pp. 843-852, 2011.

[3] S. M. AbouRizk and D. W. Halpin, "Statistical Properties of Construction Duration Data," J. Constr. Eng. Manag., vol. 118, no. 3, pp. 525$544,1992$.

[4] H. Alzraiee, T. Zayed, and O. Moselhi, "Methodology for synchronizing Discrete Event Simulation and System Dynamics models," in Proceedings of the 2012 Winter Simulation Conference (WSC), 2012, pp. 1-11.

[5] P. Lorterapong and O. Moselhi, "Project-Network Analysis Using Fuzzy Sets Theory,” J. Constr. Eng. Manag., vol. 122, no. 4, pp. 308-318, 1996.

[6] M. Khanzadi, F. Nasirzadeh, M. Mir, and P. Nojedehi, "Prediction and improvement of labor productivity using hybrid system dynamics and agent-based modeling approach," Constr. Innov., vol. 18, no. 1, pp. 2-19, 2017.

[7] S. Moradi, F. Nasirzadeh, and F. Golkhoo, "A hybrid SD-DES simulation approach to model construction projects," Constr. Innov., vol. 15, no. 1, pp. 66-83, 2015.

[8] P. Nojedehi and F. Nasirzadeh, "A hybrid simulation approach to model and improve construction labor productivity," KSCE J. Civ. Eng., vol. 21, no. 5, pp. 1516-1524, 2017.

[9] S. M. AbouRizk and A. Sawhney, "Subjective and interactive duration estimation," Can. J. Civ. Eng., vol. 20, pp. 457-470, 1993.

[10] S. M. AbouRizk, "Role of Simulation in Construction Engineering and Management," J. Constr. Eng. Manag., vol. 136, no. 10, pp. 1140$1153,2010$.

[11] A. Robinson Fayek and A. Oduba, "Predicting Industrial Construction Labor Productivity Using Fuzzy Expert Systems," J. Constr. Eng. Manag., vol. 131, no. 8, pp. 938-941, 2005.

[12] J. C. Martinez, "Methodology for Conducting Discrete-Event Simulation Studies in Construction Engineering and Management," J. Constr. Eng. Manag., vol. 136, no. 1, pp. 3-16, 2010.

[13] A. M. Law, Simulation modeling and analysis, 5th edn. New York: McGraw-Hill, 2015.

[14] M. Hajdu and O. Bokor, "Sensitivity analysis in PERT networks: Does activity duration distribution matter?," Autom. Constr., vol. 65, pp. 1$8,2016$.

[15] J. W. Forrester, Industrial dynamics. Portland, Oregon: Productivity Press, 1961.

[16] M. Kunc, "System Dynamics: A Soft and Hard Approach to Modelling," in Proceedings of the 2017 Winter Simulation Conference, 2017, pp. 597-606. 
[17] M. J. Mawdesley and S. Al-Jibouri, “Modelling construction project productivity using systems dynamics approach,” Int. J. Product. Perform. Manag., vol. 59, no. 1, pp. 18-36, 2009.

[18] P. O. Siebers, C. M. MacAl, J. Garnett, D. Buxton, and M. Pidd, "Discrete-event simulation is dead, long live agent-based simulation!," J. Simul., vol. 4, no. 3, pp. 204-210, 2010.

[19] J. W. . Son, E. M. . Rojas, and S.-W. . Shin, "Application of agent-based modeling and simulation to understanding complex management problems in CEM research,” J. Civ. Eng. Manag., vol. 21, no. 8, pp. 998-1013, 2015.

[20] A. Sawhney, H. Bashford, K. Walsh, and A. R. Mulky, "Agent-based modeling and simulation in construction," in Proceedings of the 2003 Winter Simulation Conference, 2003, pp. 1541-1547.

[21] M. Watkins, A. Mukherjee, N. Onder, and K. Mattila, "Using Agent-Based Modeling to Study Construction Labor Productivity as an Emergent Property of Individual and Crew Interactions," J. Constr. Eng. Manag., vol. 135, no. 7, pp. 657-667, Jul. 2009.

[22] S. Dabirian, M. Khanzadi, and M. Moussazadeh, "Predicting labor costs in construction projects using agent-based modeling and simulation," Sci. Iran., vol. 23, no. 1, pp. 91-101, 2016.

[23] S. C. Hsu, K. W. Weng, Q. Cui, and W. Rand, "Understanding the complexity of project team member selection through agent-based modeling,” Int. J. Proj. Manag., vol. 34, no. 1, pp. 82-93, 2016.

[24] A. Borshchev, "Multi-method modeling," in Proceedings of the 2013 Winter Simulation Conference, 2013, pp. 4089-4100.

[25] A. Borshchev and A. Filippov, "From System Dynamics and Discrete Event to Practical Agent Based Modeling: Reasons , Techniques , Tools," in Proceedings of the 22nd International Conference of the System Dynamics Society, 2004.

[26] N. Mustafee, J. Powell, S. C. Brailsford, S. Diallo, J. Padilla, and A. Tolk, "Hybrid simulation studies and Hybrid Simulation systems: Definitions, challenges, and benefits," in Proceedings of the 2015 Winter Simulation Conference, 2015, pp. 1678-1692.

[27] P. J. Mosterman, "An Overview of Hybrid Simulation Phenomena and Their Support by Simulation Packages," in Hybrid Systems: Computation and Control, 1999, pp. 165-177.

[28] M. Balaban, P. Hester, and S. Diallo, "Towards a theory of multi-method M\&S approach: Part I," in Proceedings of the 2014 Winter Simulation Conference, 2014, pp. 1652-1663.

[29] D. A. Fahrland, "Combined discrete event continuous systems simulation," Simulation, vol. 14, no. 2, pp. 61-72, 1970.

[30] F. Peña-Mora, S. Han, S. Lee, and M. Park, "Strategic-Operational Construction Management: Hybrid System Dynamics and Discrete Event Approach,” J. Constr. Eng. Manag., vol. 134, no. 9, pp. 701-710, 2008.

[31] A. Alvanchi, S. H. Lee, and S. AbouRizk, "Modeling Framework and Architecture of Hybrid System Dynamics and Discrete Event Simulation for Construction," Comput. Civ. Infrastruct. Eng., vol. 26, no. 2, pp. 77-91, 2011.

[32] H. Alzraiee, T. Zayed, and O. Moselhi, "Dynamic planning of construction activities using hybrid simulation,” Autom. Constr., vol. 49, pp. 176-192, 2015.

[33] L. Lättilä, P. Hilletofth, and B. Lin, “Hybrid simulation models - When, why, how?,” Expert Syst. Appl., vol. 37, no. 12, pp. 7969-7975, 2010.

[34] F. Nasirzadeh, M. Khanzadi, and M. Mir, “A hybrid simulation framework for modelling construction projects using agent-based modelling and system dynamics: an application to model construction workers’ safety behavior,” Int. J. Constr. Manag., vol. 3599, no. November, pp. $1-12,2017$.

[35] L. A. Zadeh, "Fuzzy Sets versus Probability,” Proc. IEEE, vol. 68, no. 3, p. 421, 1980.

[36] B. M. Ayyub and A. Haldar, "Project Scheduling Using Fuzzy Set Concepts," J. Constr. Eng. Manag., vol. 110, no. 2, pp. 189-204, 1984.

[37] A. A. Shaheen, A. Robinson Fayek, and S. M. AbouRizk, "Methodology for integrating fuzzy expert systems and discrete event simulation in construction engineering,” Can. J. Civ. Eng., vol. 36, no. 9, pp. 1478-1490, 2009.

[38] M. Raoufi, N. G. Seresht, and A. Robinson Fayek, "Overview of Fuzzy Simulation Techniques in Construction Engineering and Management," in 2016 Annual Conference of the North American Fuzzy Information Processing Society (NAFIPS), 2016, pp. 1-6.

[39] H. Zhang, C. M. Tam, and H. Li, “Modeling uncertain activity duration by fuzzy number and discrete-event simulation,” Eur. J. Oper. Res., vol. 164, pp. 715-729, 2005.

[40] M. Khanzadi, F. Nasirzadeh, and M. Alipour, "Integrating system dynamics and fuzzy logic modeling to determine concession period in BOT projects," Autom. Constr., vol. 22, pp. 368-376, 2012.

[41] D. C. De Salles, A. C. Gonçalves Neto, and L. G. Marujo, "Using fuzzy logic to implement decision policies in system dynamics models," Expert Syst. Appl., vol. 55, pp. 172-183, 2016.

[42] M. Raoufi and A. Robinson Fayek, "Integrating Fuzzy Logic and agent-based modeling for assessing construction crew behavior," in Annual Conference of the North American Fuzzy Information Processing Society - NAFIPS, 2015.

[43] C. Swinerd and K. R. McNaught, "Design classes for hybrid simulations involving agent-based and system dynamics models," Simul. Model. Pract. Theory, vol. 25, pp. 118-133, 2012.

[44] L. Florez and D. Castro-Lacouture, "Labor management in masonry construction: A sustainable approach," in 31st International Symposium on Automation and Robotics in Construction and Mining (ISARC 2014): Automation, Construction and Environment, 2014, pp. 529-536.

[45] N. Dawood, B. Hobbs, and A. Fanning, "Standardization of Brickwork Construction: Identification and Measurement of Standard Processes," in Proceedings 17th Annual ARCOM Conference, 2001, pp. 321-329.

[46] L. Florez, "Crew Allocation System for the Masonry Industry,” Comput. Civ. Infrastruct. Eng., vol. 32, no. 10, pp. 874-889, 2017.

[47] H. R. Thomas and I. Završki, “Construction baseline productivity: Theory and practice,” J. Constr. Eng. Manag., vol. 125, no. 5, pp. 295303, 1999.

[48] R. G. Sargent, "An introductory tutorial on verification and validation of simulation models," in Proceedings of the 2015 Winter Simulation Conference, 2015, pp. 1729-1740. 